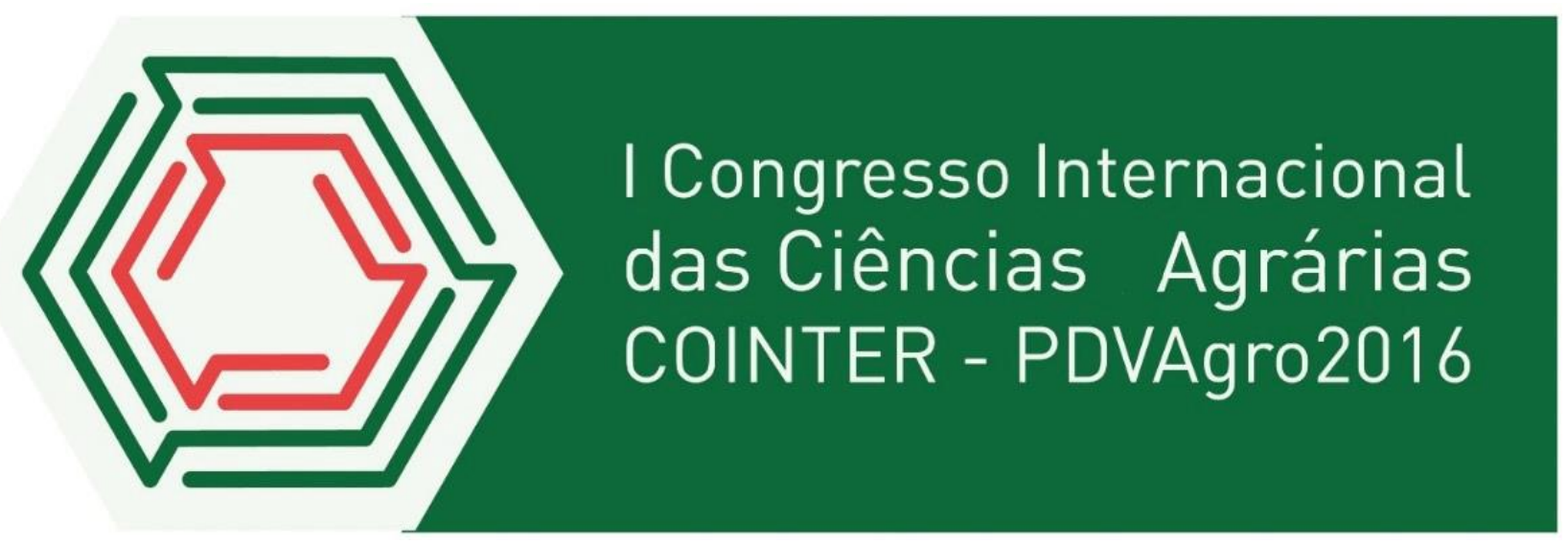

\title{
QUALIDADE MICROBIOLÓGICA DE QUEIJO DE COALHO
}

\author{
Apresentação: Pôster
}

Viviane de Oliveira Andrade ${ }^{1}$; Luciane Maria dos Anjos Bezerra ${ }^{2}$; Jardênia de Oliveira Andrade ${ }^{3}$; Mônica Maurício do Nascimento ${ }^{4}$; Emmanuel Moreira Pereira ${ }^{5}$

\section{Introdução}

O queijo, como derivado tradicional do leite, devido as suas propriedades organolépticas e nutritivas, tem grande aceitação no mercado, apresentando-se para consumo com diversas variedades quanto ao tipo, sabor, cor, forma e aroma, a fim de satisfazer aos vários paladares dosseus consumidores (NOGUEIRA, 2006).

Por suas características de processamento, os queijos produzidos artesanalmente, apresentam geralmente uma elevada quantidade de microrganismos que são responsáveis pela deterioração ou a redução da vida útil do produto ocasionada por más condições higiênicas sanitárias durante o processamento.

Vários estudos sobre a qualidade microbiológica de queijo-coalho relataram ocorrência de microrganismos patogênicos e contagem de microrganismos deterioradores em números que excedem, às vezes, os limites estabelecidos pela legislação. (CAVALCANTE et al., 2007).

A análise microbiológica nos derivados lácteos torna-se um parâmetro importante para a determinação da qualidade do produto. Diante do exposto, o presente trabalho teve como objetivo avaliar a qualidade microbiológica dos queijos de coalho durante seu armazenamento.

\footnotetext{
${ }^{1}$ Graduanda em Agroindústria, Universidade Federal da Paraíba, vivianeoliverandrade@gmail.com ${ }^{2}$ Graduanda em Agroindústria, Universidade Federal da Paraíba, lucianemariaufpb@gmail.com ${ }^{3}$ Graduanda em Nutrição, Universidade Federal de Campina Grande, jardeniadeo.andrade@gmail.com ${ }^{4}$ Graduanda em Agroindústria, Universidade Federal da Paraíba,monicamauricio5@gmail.com ${ }^{5}$ Engenheiro Agrônomo, CCHSA/UFPB, e-mail: emmanuel16mop@hotmail.com
} 


\section{Fundamentação Teórica}

O queijo coalho é considerado um produto elaborado por coagulação do leite, complementada ou não pela ação de bactérias lácteas selecionadas, com remoção do soro e aquecimento da massa até se obter uma massa semicozida ou cozida e apresentando um teor de gordura nos sólidos totais variável entre $35,0 \%$ e 60,0\%. Nessa massa é adicionado o cloreto de sódio e a mesma é prensada, secada e embalada para estocagem (BRASIL, 2001).

Este queijo por ser um produto derivado do leite, oferece excelentes condições para proliferação de microrganismos deterioradores e de microrganismos patogênicos (CAVALCANTE et al., 2007).

A presença de coliformes e Mesofilos são indicadores da qualidade higiênica dos alimentos. Staphylococcus aureus que é toxigênico e produtor de toxina termoestável pré-formada no alimento. A Salmonella spp. é uma bactéria responsável por casos de intoxicação alimentar, frequentemente observada em queijo coalho(DUARTE et al., 2005;SALOTTI et al., 2006). Esses parâmetros microbiológicos fornecem uma ideia sobre o tempo útil de conservação dos produtos.

\section{Metodologia}

\section{Local do trabalho}

As determinações microbiológicas foram realizadas no Laboratório de microbiologia pertencente ao CCHSA/Campus III - Bananeiras/PB da Universidade Federal da Paraíba, o período de desenvolvimento tendo duração de 42dias, sendo realizada uma pesquisa experimental.

\section{Preparo da amostra}

O queijo coalho foi adquirido nafeira livre do município de Bananeiras/PB, onde é comercializado. Aproximadamente $1 \mathrm{~kg}$ de queijo, foi dividido em 6 amostras com aproximadamente 150 gcada, sendo embaladas a vácuo e armazenadas em incubadora BOD a $4{ }^{\circ} \mathrm{C}$ e analisada a cada 8 dias durante o período de 42 dias de armazenamento.

As embalagens foram desinfetadas com álcool 70\%. Foram retiradas $25 \mathrm{~g}$ da amostra e homogeneizados juntamente com $225 \mathrm{~mL}$ de água peptonada $0,1 \%$ estéril (diluição $10^{-1}$ ). A partir desta foram feitas sucessivas diluições decimais (APHA, 1992). 


\section{Análises Microbiológicas}

As análises microbiológicas dos queijos foram realizadas em triplicata, seguindo os procedimentos gerais (diluições, plaqueamento, repetições e contagens) descritos no APHA (1992).

As bactérias mesófilas foram determinadas em placas com Plate Count Agar (PCA) incubadas a $35{ }^{\circ} \mathrm{C}$ por 48 horas. Os resultados foram expressos em Unidade Formadora de Colônias por grama de queijo (UFC. $\mathrm{g}^{-1}$ ).

Para a análise de coliformes totais e termotolerantes, utilizou-se a tabela do NMP/g pela técnica de tubos múltiplos com diluições $10^{-1}, 10^{-2}$ e $10^{-3}$ em caldo lactosado (CL), para pesquisa presuntiva de coliformes totais e caldo verde brilhante (VB) como método confirmativo. Para confirmação contaminação por bactérias termotolerantes usou-se como meio de cultura o CEC, sendo considerados positivos os que apresentaram formação de gás no interior dos tubos de Durhan.

Para a contagem de Staphylococcus aureus, as amostras diluídas foram inoculadas na superfície de placas contendo Ágar Baird-Parker. Após o término das operações, as placas foram incubadas em posição invertida, à temperatura de $35^{\circ} \mathrm{C}$ por 48 horas. Os resultados foram expressos em $\left(U F C \cdot g^{-1}\right)$.

Para a pesquisa de Salmonellasp. as amostras foram pré-enriquecidas em água peptonada a $1 \%$ (AP) e incubadas a $35^{\circ} \mathrm{C}$ por um período de 24 horas. Após o término deste tempo iniciou-se o processo de enriquecimento seletivo, onde foram transferidasalíquotas de $1 \mathrm{ml}$ da cada amostra para 2 tubos de ensaio contendo aproximadamente $10 \mathrm{ml}$ de caldo selenito cistina (CSC), e outro contendo caldo tetrationato (CTT), sendo incubados a $35^{\circ} \mathrm{C}$ durante $24 \mathrm{~h}$. Do crescimento nos meios de enriquecimento seletivo foram transferidos, com o auxilio de uma alça de semeadura, alíquotas do inoculo para placas contendo os meios, Ágar Salmonella Diferencial (SD) e Ágar Salmonela Shigella (SS) e incubadas a $37^{\circ} \mathrm{C}$ por $24 \mathrm{~h}$ e o resultado final foi determinado pelo aspecto do crescimento de colônias.

\section{Resultados e Discussões}

$\mathrm{Na}$ Tabela 1 são apresentados os resultados da determinação de coliformes totais e termotolerantes, contagem de bactérias mesófilas, Staphylococcus coagulase positiva e Salmonellaspp. nas amostras de queijo de coalho. 
Tabela 1 - Caracterização Microbiológica de queijos de coalho durante o armazenamento. Fonte própria

\begin{tabular}{|c|c|c|c|c|c|c|}
\hline \multirow{2}{*}{ MICROORGANISMOS } & \multicolumn{6}{|c|}{ PERÍODOS } \\
\hline & $\mathbf{0}$ & 1 & 2 & 3 & 4 & 5 \\
\hline Colifomes Totais (NMP/g) & $1,1 \times 10^{5}$ & $1,1 \times 10^{5}$ & $1,1 \times 10^{5}$ & $1,1 \times 10^{5}$ & $1,1 \times 10^{5}$ & $1,1 \times 10^{5}$ \\
\hline ColifomesTermotolerantes(NMP/g) & $8,3 \times 10^{5}$ & $<3$ & $<3$ & $<3$ & $<3$ & $<3$ \\
\hline Mesófilos (UFC/g) & $3,5 \times 10^{6}$ & $2,3 \times 10^{6}$ & $3,8 \times 10^{7}$ & $1,7 \times 10^{8}$ & $1,9^{5} \times 10^{8}$ & $2,0 \times 10^{8}$ \\
\hline Staphilococcuscoagulase positiva & Ausência & $2,2 \times 10^{4}$ & Ausência & Ausência & Ausência & Ausência \\
\hline Salmonellasp. & Ausência & Ausência & Ausência & Ausência & Ausência & Ausência \\
\hline
\end{tabular}

De acordo com os resultados da análise microbiológica detectou-se que a presença de coliformes totais e termotolerantes ficaram acima do permitido pela Legislação Brasileira RDC $\mathrm{n}^{\circ} 12$ (Tabela 1) que apresenta como limite de tolerância de 5 x $10^{2} \mathrm{NMP} / \mathrm{g}$. Resultados encontrados neste estudo são similares aos encontrados por Dantas (2012) quando estudou a qualidade microbiológica do queijo de coalho.Vale ressaltar que os termotolerantes na amostra analisada houve crescimento apenas no primeiro período com um valor superior, supondo que a amostra passou por uma possível contaminação no processo de elaboração ou durante a análise.

Observou-se que o produto analisado apresentou uma elevada população de bactérias aeróbias mesófilas (Tabela 1), resultados semelhantes foram encontrados por Scheid Filho et al. (2004), ao avaliarem a qualidade microbiológica do queijo colonial segundo os autores, pode ser decorrente de condições precárias de higiene na produção, processamento e/ou manipulação do produto, assim como da falta de pasteurização e controle de qualidade da matéria-prima.

Para Staphylococcus coagulase positiva obteve-se resultados que permaneceram fora do máximo permitido apenas em um período (Tabela 1).Santana (2008)encontrou uma alta incidência de S. aureus em estudo com queijo coalho. Assumpção et al. (2003), verificaram que a presença desses microrganismos nas mãos e antebraço dos manipuladores foi a responsável pela contaminação do queijo, pois ocorreu em etapas posteriores à inativação dos microrganismos por pasteurização. Essa observação pode ser empregada para explicar a incidência em um dos períodos na amostra de queijo estudada.

Não foi verificado presença de Salmonella sp em nenhum dos períodos avaliados (Tabela 1), sendo este um resultado satisfatório por estar dentro dos padrões estabelecidos pela Anvisa (Brasil, 2001), que estabelecem ausência desse micro-organismo em 25 g de alimento. Sangaletti (2007) e Ávila e Gallo (1996) também não observaram a presença de Salmonella spp. , ambos em estudo com queijo minas frescal. 


\section{Conclusões}

O queijo de coalho apresentou condições higiênico-sanitárias satisfatórias ao longo do período de armazenamento, a contaminação por coliformes termotolerantes e Staphylococcus coagulase positiva evidenciada em um único período pode ter sido ocasionada durante a manipulação da amostra.

\section{Referências}

AMERICAN PUBLIC HEALTH ASSOCIATION - APHA.Standard methods for the examination of dairy products. Washington, $1992.345 \mathrm{p}$.

ANDRADE, A.A. de. Estudo do perfil sensorial, físico-químico e aceitação de queijo de coalhoproduzido no estado do Ceará.104p. 2006. Dissertação (Mestre em Tecnologia de Alimentos) - Universidade Federal do Ceará, Fortaleza, 2006.

ASSUMPÇÃO, E.G.; PICCOLI-VALLE, R.H.; HIRSCH, D. et al. Fontes de contaminação por Staphylococcus aureus na linha de processamento de queijo prato.Arquivo Brasileiro de Medicina Veterinária e Zootecnia. v.55, p.366-370, 2003.

ÁVILA, C.R.; GALLO, C.R. Pesquisa de Salmonellaspp. em leite cru, leite pasteurizado queijo tipo "minas frescal" comercializados no município de Piracicaba. SP.Scientia Agricola, v.53, p.159-163, 1996.

BRASIL. Agência Nacional de Vigilância Sanitária. Resolução RDC n.12, de 2 de janeiro de 2001. Aprova o regulamento técnico sobre padrões microbiológicos para alimentos.Disponível em: <http://www. anvisa.gov.br/legis/resol>. Acesso em: 04 set. de 2016.

DANTAS, D. S. Qualidade Microbiológica do queijo de coalho comercializado no Município de Patos, PB. 79 p. 2012. Dissertação (Mestrado em Zootecnia), Universidade Federal de Campina Grande, Centro de Saúde e Tecnologia Rural,Patos, 2012.

CAVALCANTE, J.F.M.; ANDRADE, N.J.; FURTADO, M.M. et al. Processamento do queijo coalho regional empregando leite pasteurizado e cultura lática endógena. Ciência e TecnologiaAlimentar, v.27, p.205-214, 2007.

NASSU, R.T.; MACEDO, B.A.; LIMA, M.H.P. Queijo de Coalho. Coleção Agroindústria Familiar. Embrapa Informação Tecnológica. v.1, p.40. Brasília, DF, 2006.

NOGUEIRA, J. G. A embalagem como fator de agregação de valor ao produto: Um estudo do segmento de queijos em Juiz de Fora. Universidade Federal Fluminense. Sistema de Gestão, Dissertação (mestrado) Área Sistema de Gestão pela Qualidade Total, Niterói, 2006.

SAlOTTI, B.M.; CARVALHO, A.C.F.B.; AMARAL, L.A.; VIDAL, A.M.C.; CORTEZ, A.L. Qualidade microbiológica do queijo minas frescal comercializado no município de Jaboticabal, SP, Brasil. Arquivos do Instituto Biológico, São Paulo, v.73, n.2, p.171-175, 2006. 
SANGALETTI, N.; Estudo da vida útil do queijo Minas frescal disponível no mercado. Dissertação (Mestrado) - Escola Superior de Agricultura Luiz de Queiroz, Piracicaba, 2007.

SANTANA, R. F. et al. Qualidade microbiológica de queijo-coalho comercializado em Aracaju, SE.Arquivo Brasileiro de Medicina Veterinária e Zootecnia. Minas Gerais, v.60, n.6, p.1517-1522, 2008.

SCHEID FILHO, V.B.; ROOS, T.B.; OLIVEIRA, D.S.; TIMM, C.D. Contagem de bactérias mesófilas e psicrotróficas em queijo colonial. In: Congresso Brasileiro de Microbiologia, 22, 2004, 